Original Research Article

\title{
Pharmacoepidemiological profile and appropriateness of drug use in paediatric diarrhoea patients: a cross sectional study in western India
}

\author{
Vipul P. Chaudhari' ${ }^{1}$, Juhi Patel ${ }^{2}$, Rima Shah ${ }^{2 *}$, Amit Shah ${ }^{3}$
}

${ }^{1}$ Department of Pharmacology, GCS Medical College, Ahmedabad, Gujarat, India ${ }^{2}$ Department of Pharmacology, GMERS Medical College, Gandhinagar, Gujarat, India ${ }^{3}$ Department of Pharmacology, GMERS Medical College, Dharpur, Patan, Gujarat, India

Received: 17 June 2017 Accepted: 10 July 2017

*Correspondence to:

Dr. Rima Shah,

Email: rima_1223@yahoo.co.in

Copyright: (C) the author(s), publisher and licensee Medip Academy. This is an openaccess article distributed under the terms of the Creative Commons Attribution NonCommercial License, which permits unrestricted noncommercial use, distribution, and reproduction in any medium, provided the original work is properly cited.

\begin{abstract}
Background: The background of the study was to analyze the prescribing pattern and appropriateness of drug treatment of diarrhoea.

Methods: Total 194 pediatric patients with diarrhoea (140 admitted at tertiary care centre and 54 patients attended primary health care centre) were included and their demographic details; disease related parameters, drug treatment and adverse drug reactions were recorded. Appropriateness of drug treatment was analyzed using the WHO and Indian Academy of Pediatrics (IAP) guidelines for management of diarrhoea.
\end{abstract}

Results: Most patients (27.32\%) were less than 1 year of age and majority $54.64 \%$ were males. Most common presenting symptoms was diarrhoea with dehydration $(100 \%)$ followed by vomiting $(60 \%)$, fever $(54.29 \%)$. Stool cultures were carried out only in $22.86 \%$ patients at tertiary health care centre while no investigations were carried out at PHC. Average number of drugs prescribed per patient was $8.25 \pm 1.3$. All the patients were given fluid replacement therapy. $94.29 \%$ and $85.19 \%$ patients were prescribed antimicrobials at tertiary centre (THC) and PHC respectively. Most common antibiotic used was cephalosporins (82\%) followed by aminoglycosides $(48.57 \%)$ of patients at THC while ofloxacin $(82.60 \%)$ and metronidazole $(17.40 \%)$ were commonly used at PHC. Analgesic/antipyretic was required in $70.71 \%$ and $85.19 \%$ of patients at THC and PHC respectively. Comparing with the WHO diarrhoea management guidelines and IAP guidelines, only $8(14.81 \%)$ prescriptions were considered as rational. $2.85 \%$ patients developed mucocutaneous rash as ADR.

Conclusions: Inappropriate prescribing for diarrhoea is highly prevalent in society. Emphasis on proper diagnosis and treatment, education and availability of locally effective guidelines may help in a better and judicious use of drugs in children.

Keywords: Comparison of primary and tertiary care for diarrhoea, Diarrhoea, Drug utilization, Pediatric patients, WHO diarrhoea management guidelines, IAP diarrhoea management guidelines

\section{INTRODUCTION}

Each year, an estimated 2.5 billion cases of diarrhoea occur among children under five years of age, and estimates suggest that overall incidence has remained relatively stable over the past two decades. ${ }^{1}$ Diarrhoea is a leading cause of death in children, accounting for $9 \%$ of all deaths among children under age 5 worldwide in 2015. This translates into over 1,400 young children dying each day, or about 530,000 children a year, despite the availability of simple effective treatment. ${ }^{2}$ According to the recent report of UNICEF, most deaths from diarrhoea occur among children less than 2 years of age living in South Asia and sub-Saharan Africa and also they are more likely to result in death or other sever outcomes. Despite this heavy toll, progress is being made that in the period from year 2000 to 2015, the total annual number of deaths from diarrhoea among children under 5 decreased by more than 50 per cent - from over 1.2 million to half a million. ${ }^{2}$ In India, diarrhoeal disease accounts for $8.2 \%$ of total burden of disease, contributing 22 million Disability Adjusted Life Years (DALYs), the highest among communicable 
diseases. $^{3}$

Diarrhoea is defined as having loose or watery stools at least three times per day, or more frequently than normal for an individual. The incidence of diarrhoeal diseases varies greatly with the seasons and a child's age. The youngest children are most vulnerable: Incidence is highest in the first two years of life and declines as a child grows older. ${ }^{1}$ Though most episodes of childhood diarrhoea are mild, acute cases can lead to significant fluid loss and dehydration, which may result in death or other severe consequences if fluids are not replaced at the first sign of diarrhoea. ${ }^{1}$

Drug use in children has not been as extensively researched as in adults. It has been observed that $18.2 \%$ of children receive drugs that are not required. ${ }^{4}$ This has a negative impact on quality of life and can result in considerable healthcare costs. ${ }^{5,6}$ The use of low osmolarity ORS and zinc supplementation in all cases of diarrhoea in addition to breast feeding, continued feeding and selective use of antibiotics help in reducing morbidity and mortality due to diarrhoea. ${ }^{7,8}$ The WHO estimates that most of the diarrhoea are viral in origin and self-limiting which does not require antimicrobial therapy. Antibiotic treatment is necessary in only one in twenty cases of childhood diarrhoea. ${ }^{9,10}$ Large resources are currently spent on antidiarrhoeal drugs annually, most of which are useless or harmful in pediatric patients. Therapeutic guidelines have been issued by the WHO and Indian Academic of Pediatrics (IAP), which aim at reducing the inappropriate use of antimicrobials and anti-diarrhoeal drugs in treatment of diarrhoea. ${ }^{11-13}$ Drug utilization research generates baseline data for the prevalence of different diseases and drug therapy used and also evaluates effectiveness of the guidelines. It also identifies the grass root level problems in the management of diarrhoea and can be helpful in setting the agenda for further investigations directed at reducing morbidity and mortality by this disease. It also helps in allocating the resources and improving rational drug use. ${ }^{12}$

Considering all above mentioned facts, the present drug utilization study was designed to identify the prevalence of different diseases causing diarrhoea in pediatric patients, demographic and clinical profile of the pediatric patients having diarrhea and to study the drug utilization pattern among them like type of drug use, route, dose, frequency of administration, duration of therapy etc. The appropriateness of the drug therapy prescribed was evaluated by comparing it with WHO and IAP diarrhoea management guidelines.

\section{METHODS}

This was a cross-sectional survey to examine the common diseases causing diarrhoea, their pharmacological management and appropriateness of drug use in pediatric patients.

\section{Study participants}

The study was conducted in the paediatric department of a tertiary care teaching hospital of western India. All the patients admitted to pediatric indoor unit between March to August 2014 were screened. Patients attending to a primary health care centre (PHC) of the same region in the defined time period were also screened. All the children aged between 1 month to 12 years and of either gender and diagnosed by the pediatrician to be suffering from acute diarrhoea were included in the study. Patients who were having severely illness requiring intensive care unit admission, patients suffering from persistent or chronic diarrhoea and those who had taken discharge against medical advice were excluded from the study.

\section{Sample size and power estimation}

The primary objective was to assess prevalence of diarrhoea in the pediatric community requiring hospitalization and to evaluate appropriateness of drug use in them. Assuming a prevalence rate of inappropriate treatment in diarrhoea in pediatric patients as high as $50 \%$, and $\alpha=0.05$ (two-tailed), 96 patients were needed to give an estimate at a width of $\pm 10 \%$ and with a $95 \%$ confidence interval (CI). ${ }^{14}$ Assuming some dropouts, 140 patients were recruited for the study from the tertiary care centre.

The study protocol was approved by the local Institutional Ethics Committee. Parents/guardians of the children were explained clearly about the nature and purpose of the study in the language they understand. Written informed consent was obtained from the parent/guardian before enrolling the patient for the study. Permission from Medical Superintendent of the hospital and the Head of the pediatric department was obtained before conducting the study.

\section{Study procedure and data collection}

Patients meeting inclusion and exclusion criteria were visited daily by the researcher throughout the hospital stay in the tertiary care hospital till patient discharged from the hospital. Patients attending to PHCs were interviewed once only at the time of their visit. All necessary information like demographic data, history of illness, other relevant clinical data, laboratory investigations and drug treatment was collected by reviewing the hospital case file and by interview with parents/children. All these data were recorded in the structured and pre-tested case record form. The immunization status was determined in reference to the national immunization schedule. ${ }^{7}$

All the adverse drug reactions either self-reported or identified by the researcher during the visits were also monitored and reported. Causality assessment of the reported ADRs was carried out using WHO-UMC criteria. ${ }^{15}$ The investigator was not the part of the treating team of the patients and was not involved in any treatment related decisions. 


\section{Data analysis}

All the gathered data was analyzed for demographic parameters like age and gender wise distribution of patients, prevalence of different diseases causing diarrhoea, association with malnutrition and other symptoms, duration of hospital stay, drug treatment given with its route, dose, frequency and duration of treatment. Appropriateness of the drug treatment was evaluated by comparing the given treatment with WHO treatment guidelines and IAP guidelines. ${ }^{8} 10$ Any deviation from the treatment guidelines was considered as inappropriate treatment. Drug treatment differences between PHC and tertiary care hospital were also studied.

\section{Statistical analysis}

Patient demographic information and drug usage were expressed in actual frequencies, percentage, mean, standard deviation as appropriate. The difference in proportions will be measured by chi-square test and $\mathrm{p}$ value less than 0.05 was considered significant. The statistical analysis of data was carried out using Microsoft excel 2007.

\section{RESULTS}

A total of 194 patients of diarrhoea (140 admitted at tertiary care centre and 54 attended a primary health care centre) were enrolled over the period of 6 months (MarchAugust 2014). The mean age of the patients was 2.1 2.84 years with a range of 1 month to 11 years. Most patients $(27.32 \%)$ were less than 1 year of age. Out of these 194 patients, $106(54.64 \%)$ were males and $88(45.36 \%)$ were females. A total of $75.77 \%$ patients were fully immunized as per the National Immunization Schedule. Baseline parameters and demographic details of the patients had been shown in Table 1.

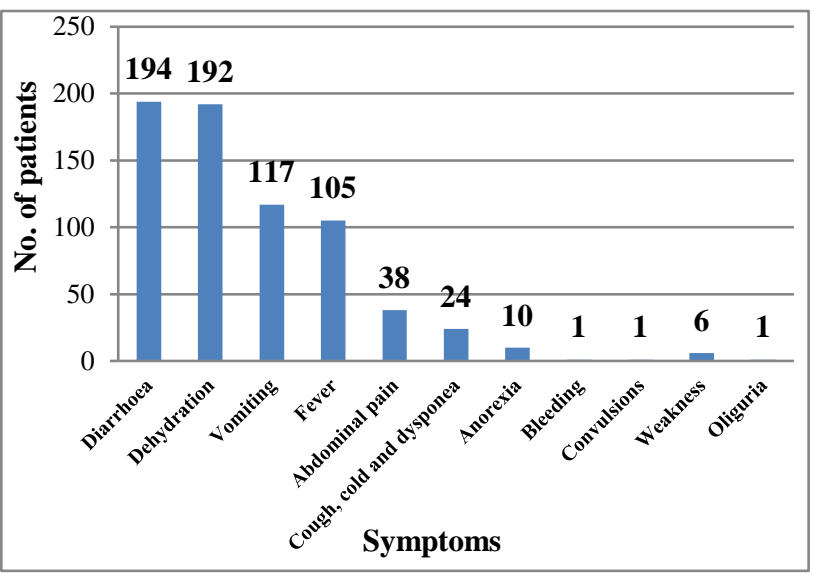

Figure 1: Presenting symptoms of diarrhoea patients $(n=194)$.

Out of 140 inpatients at tertiary care centre 17 (12.14\%), $70(50 \%)$ and $53(37.86 \%)$ were diagnosed with no, some and severe dehydration, respectively. But at PHC, majority
44 (81.48) patients had some dehydration. At tertiary care centre, majority $(78.57 \%)$ patients were diagnosed as suffering from acute gastroenteritis clinically, while rest $21 \%$ had other illnesses also like respiratory infection, malaria, typhoid etc. while at PHC none of the patient had any complication/co-morbid conditions.

Table 1: Demographic parameters and disease related factors of the study population: $(n=194)$.

\begin{tabular}{|c|c|c|c|}
\hline Parameter & $\begin{array}{l}\text { No. of } \\
\text { patients at } \\
\text { tertiary } \\
\text { care centre } \\
(n=140, \%)\end{array}$ & $\begin{array}{l}\text { No. of } \\
\text { patients } \\
\text { at PHC } \\
(\mathrm{n}=54, \\
\%)\end{array}$ & $\begin{array}{l}\text { Total } \\
(n=194, \\
\%)\end{array}$ \\
\hline \multicolumn{4}{|l|}{ Age in years } \\
\hline $0-1$ & $51(36.43)$ & $2(3.70)$ & $53(27.32)$ \\
\hline $1-2$ & $34(24.29)$ & $10(18.52)$ & $44(22.68)$ \\
\hline $2-3$ & $15(10.71)$ & $8(14.81)$ & $23(11.86)$ \\
\hline $3-4$ & $16(11.43)$ & $15(27.78)$ & $31(15.98)$ \\
\hline $4-5$ & $24(17.14)$ & $19(35.19)$ & $43(22.16)$ \\
\hline \multicolumn{4}{|l|}{ Gender } \\
\hline Male & $76(54.29)$ & $30(55.56)$ & $106(54.64)$ \\
\hline Female & $64(45.71)$ & $24(44.44)$ & $88(45.36)$ \\
\hline \multicolumn{4}{|c|}{ Body weight in $\mathrm{Kg}$} \\
\hline $1-5$ & $9(6.43)$ & $1(1.85)$ & $10(5.15)$ \\
\hline $5.1-10$ & $91(65)$ & $19(35.19)$ & $110(56.70)$ \\
\hline $10.1-20$ & $40(28.57)$ & $34(62.96)$ & $74(38.14)$ \\
\hline \multicolumn{4}{|c|}{ Immunization status } \\
\hline Complete & $105(75)$ & $42(77.78)$ & $147(75.77)$ \\
\hline Partial & $21(15)$ & $8(14.81)$ & $29(14.95)$ \\
\hline $\begin{array}{l}\text { Non- } \\
\text { immunized }\end{array}$ & $12(8.57)$ & 0 & $12(6.19)$ \\
\hline Unknown & $2(1.43)$ & $4(7.41)$ & $6(3.09)$ \\
\hline \multicolumn{4}{|c|}{ Dehydration status } \\
\hline $\begin{array}{l}\text { No } \\
\text { dehydration }\end{array}$ & $17(12.14)$ & $10(18.52)$ & $27(13.92)$ \\
\hline $\begin{array}{l}\text { Some } \\
\text { dehydration }\end{array}$ & $70(50)$ & $44(81.48)$ & $114(58.76)$ \\
\hline $\begin{array}{l}\text { Severe } \\
\text { dehydration }\end{array}$ & $53(37.86)$ & 0 & $53(27.32)$ \\
\hline \multicolumn{4}{|c|}{ Duration of stay } \\
\hline $1-3$ & $88(62.86)$ & 0 & \\
\hline $3-6$ & $42(30)$ & 0 & \\
\hline$\geq 7$ & $10(7.14)$ & 0 & \\
\hline \multicolumn{4}{|l|}{ Diagnosis } \\
\hline $\begin{array}{l}\text { Acute } \\
\text { gastroenteritis } \\
\text { (AGE) }\end{array}$ & $110(78.57)$ & $54(100)$ & $164(84.54)$ \\
\hline $\begin{array}{l}\text { AGE with } \\
\text { complications }\end{array}$ & 30 & 0 & $30(15.46)$ \\
\hline
\end{tabular}

Common symptomatology of patients with diarrheal diseases is shown in Figure 1. Most common presenting symptom was diarrhoea in all patients, followed by vomiting in $60 \%$ of patients and fever in $54.29 \%$ of patients. Thorough history was followed by different 
laboratory investigations for identification of the cause of diarrhea. Complete blood count was carried out in all $100 \%$ of patients followed by serum electrolytes in $25 \%$ patients. Stool examination was carried out in only $22.86 \%$ of patients as shown in Figure 2. None of these investigations were performed at PHC.

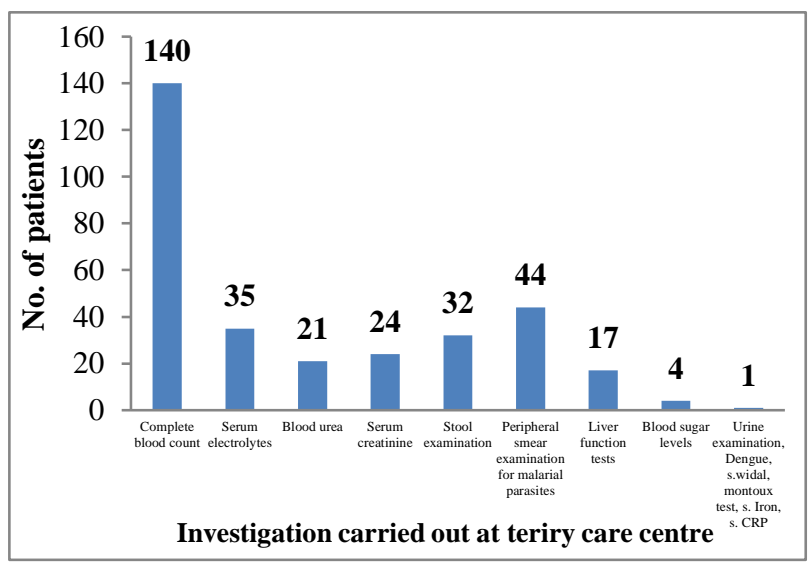

Figure 2: Investigations carried out at tertiary care hospital for diarrhoea patients $(n=140)$.

Duration of hospital stay ranged from 1 to 12 days with an average of an average of $4.3 \pm 2.1$ days. Majority had duration of hospital stay upto 3 days $(63 \%)$. The average duration of diarrhoea was $2.34 \pm 1.61$ days in inpatients with a frequency of 4 to 15 diarrhoeal episodes per day.

\section{Analysis of drug use at tertiary care centre}

The mean number of drugs prescribed per patient was $8.25 \pm 1.3$ (range 4 to 13 ). All the patients were given fluid replacement therapy, of which all $100 \%$ patients received Oral rehydration therapy and $97.14 \%$ had received intravenous fluids. Duration of ORS therapy ranged from 1-8 days, with majority of patients received ORS for upto 3 days. Among IV fluids, isolyte $\mathrm{P}$ was most frequently used in $88(62.85 \%)$ of patients followed by ringer lactate in $67(47.86 \%)$ of patients. Duration of IV therapy ranged from 1-6 days, but majority $(64.29 \%)$ required IV therapy for 1 day only. Zinc supplementation was prescribed as 20 $\mathrm{mg}$ once a day for 14 days in $79.29 \%$ of patients (Table 2).

Antimicrobial were prescribed in 132 (94.29\%) of patients. Number of antimicrobial agents prescribed was ranged from 1-4. Single antibiotic was prescribed in $32.86 \%$ of patients only. Most common antibiotic used was cephalosporins in $82 \%$ of patients followed by aminoglycosides in $48.57 \%$ of patients. Duration of antibiotic use was 1-10 days. Analgesic/antipyretic was required in $70.71 \%$ of patients, of which 99 received paracetamol and 13 patients received dicyclomin. Duration of use of analgesic/antipyretics ranged from 1-10 days. Antiemetics were prescribed to 118 (84.29\%) patients. $85(60.71 \%)$ patients received lactobacillus and $59(42.14 \%)$ received anti-acidity drugs. None of the patient was prescribed antimotility drugs (Table 2).
Table 2: Analysis of drugs used at tertiary care centre: $(n=140)$.

\begin{tabular}{|c|c|}
\hline Drug & No. of patients \\
\hline Fluid replacement therapy & $140(100)$ \\
\hline ORS & $140(100)$ \\
\hline Duration of ORS therapy & 1-8 days \\
\hline IV fluid replacement & $136(97.14)$ \\
\hline DNS & $7(5)$ \\
\hline Isolyte P & $88(62.85)$ \\
\hline $\mathrm{RL}$ & $67(47.86)$ \\
\hline NS & $8(5.71)$ \\
\hline Duration of IV therapy & 1-6 days \\
\hline $\begin{array}{l}\text { Zinc supplementation } 20 \mathrm{mg} \text { OD } \\
\text { for } 14 \text { days }\end{array}$ & $111(79.29)$ \\
\hline Antibiotics & $132(94.29)$ \\
\hline \multicolumn{2}{|l|}{ Number of antibiotics prescribed } \\
\hline 1 & $46(32.86)$ \\
\hline 2 & $66(47.14)$ \\
\hline 3 & $16(11.43)$ \\
\hline 4 & $4(2.86)$ \\
\hline \multicolumn{2}{|l|}{ Class of antibiotics used } \\
\hline Aminoglycosides (amikacin) & $68(48.57)$ \\
\hline Cephalosporins & $115(82.14)$ \\
\hline $\begin{array}{l}\text { - Ceftriaxone } \\
\text { - Cefixime } \\
\text { - Cefotaxime } \\
\text { - Cefpodoxime }\end{array}$ & $\begin{array}{ll}- & 55 \\
- & 12 \\
- & 66 \\
- & 1\end{array}$ \\
\hline $\begin{array}{l}\text { B - Lactum antibiotics } \\
\text { (Amoxicillin, Ampicillin, } \\
\text { Amoxicillin + clavuninic acid) }\end{array}$ & $10(7.14)$ \\
\hline Fluroquinolones & $12(8.57)$ \\
\hline $\begin{array}{ll}\text { - } & \text { Norfloxacin } \\
\text { - } & \text { Ciprofloxacin } \\
\end{array}$ & $\begin{array}{ll}\bullet & 11 \\
\bullet & 1\end{array}$ \\
\hline Antihelmintic drugs (Albendazole) & $8(5.71)$ \\
\hline Duration of antibiotic use & 1-10 days \\
\hline \multicolumn{2}{|l|}{ Supporting medicines } \\
\hline Analgesics/antipyretics & $99(70.71)$ \\
\hline $\begin{array}{ll}\text { - } & \text { Paracetamol } \\
\text { - } & \text { Dicyclomin } \\
\text { - } & \text { Duration of use }\end{array}$ & $\begin{array}{l}99 \\
13 \\
1-10 \text { days }\end{array}$ \\
\hline Antiemetics & $118(84.29)$ \\
\hline $\begin{array}{ll}\text { - } & \text { Ondensetron } \\
\text { - } & \text { Domperidone }\end{array}$ & $\begin{array}{l}84 \\
29\end{array}$ \\
\hline Lactobacillus & $85(60.71)$ \\
\hline $\begin{array}{ll}\text { - } & \text { Sporolac } \\
\text { - } & \text { Duration of use }\end{array}$ & $\begin{array}{l}85 \\
1-6 \text { days }\end{array}$ \\
\hline Antiacidity drugs & $59(42.14)$ \\
\hline $\begin{array}{l}\text { - Ranitidine } \\
\text { - Famotidine } \\
\text { - } \text { Duration of use }\end{array}$ & $\begin{array}{l}51 \\
8 \\
1-5 \text { days }\end{array}$ \\
\hline
\end{tabular}

\section{Analysis of drug use at PHC}

All 54 patients from PHC had received ORS and zinc supplementation. Antimicrobials were prescribed to 46 
$(85.19 \%)$ patients. Majority of patients had received ofloxacin $(38,82.60 \%)$ and rest had received metronidazole $(8,17.40 \%)$. Average duration of antimicrobial prescription was 3-5 days. Paracetamol for symptomatic relief was prescribed to $46(85.19 \%)$ patients. Comparison of drug treatment at both tertiary centre and PHC is shown in Table 3.

Table 3: Comparison of drug treatment at PHC and tertiary care center.

\begin{tabular}{|c|c|c|}
\hline Drug & $\begin{array}{l}\text { Tertiary care } \\
\text { centre }\end{array}$ & $\begin{array}{l}\text { Primary health } \\
\text { care centre }\end{array}$ \\
\hline ORS & $140(100)$ & $54(100)$ \\
\hline IV fluids & $136(97.14)$ & 0 \\
\hline $\begin{array}{l}\text { Zinc } \\
\text { supplementation }\end{array}$ & $111(79.29)$ & $54(100)$ \\
\hline $\begin{array}{l}\text { Antimicrobial } \\
\text { use }\end{array}$ & $132(94.29)$ & $46(85.19)$ \\
\hline $\begin{array}{l}\text { No of } \\
\text { antimicrobials } \\
\text { prescribed }\end{array}$ & $1-4$ & 1 \\
\hline $\begin{array}{l}\text { Class of } \\
\text { antimicrobial use }\end{array}$ & $\begin{array}{l}\text { 1. Cephalosporin } \\
-(82.14) \\
2 . \\
\text { Aminoglycosides } \\
\text {-amikacin }(48.57)\end{array}$ & $\begin{array}{l}1 . \\
\text { Fluoroquinolones - } \\
\text { Ofloxacin }(82.60) \\
\text { 2. Metronidazole } \\
(17.40)\end{array}$ \\
\hline $\begin{array}{l}\text { Duration of } \\
\text { antimicrobials }\end{array}$ & 1-10 days & 3-5 days \\
\hline \multicolumn{3}{|c|}{ Supporting medicines } \\
\hline Paracetamol & $99(70.71)$ & $46(85.19)$ \\
\hline Dicyclomine & $13(9.29)$ & 0 \\
\hline Antiemetics & $118(84.29)$ & 0 \\
\hline Lactobacillus & $85(60.71)$ & 0 \\
\hline Antiacidity drugs & $59(42.19)$ & 0 \\
\hline
\end{tabular}

\section{Evaluation of appropriateness}

While comparing with the WHO diarrhoea management guidelines and IAP guidelines, none of the prescription could be considered rational.

\section{At tertiary care centre}

\section{Rehydration therapy}

ORS and IV fluids were considered as appropriate as per the WHO and IAP guidelines. Dose, duration and frequency of administration of ORS was as per the guidelines. For intravenous hydration, Isolyte $\mathrm{P}$ was administered to most patients, which was not as per the WHO/IAP guidelines.

\section{Zinc supplementation}

Zinc salts were prescribed to $111(79.29 \%)$ patients but as per IAP and WHO guidelines but they should be prescribed to all the patients.

\section{Antibiotics}

According to WHO and IAP guidelines Antibiotics should be used in patients with septicemia, dysentery or any other patients having evidence of bacterial infection on microbiological examination, blood in stool, cholera, typhoid or any other laboratory investigation based confirm diagnosis requiring antibiotics. In this study, antibiotics were prescribed to $132(94.29 \%)$ patients while complete blood count and stool examination was carried out in $100 \%$ and $22 \%$ of patients respectively. In our study, antimicrobial use was justified only in $10(7.14 \%)$ of patients. Single effective antibiotic is sufficient for treatment of diarrhoea but multiple antimicrobials were prescribed in this study.

\section{Supporting medicines}

According to WHO and IAP guidelines, supporting medicines like paracetamol for fever and pain, domperidone/metoclopramide for vomiting and ondensatrone for severe vomiting can be given to patients if required. No lactobacillus/racicadrotil/antimotility drugs were supported by guidelines. In this study Lactobacillus was prescribed to $85(60.71 \%)$ patients and antiacidity drugs like ranitidine/famotidine were prescribed to 59 $(42.14 \%)$ of patients.

Considering all facts, none of prescriptions from tertiary care centre was considered as appropriate as per guidelines.

\section{At PHC}

Use of ORS and zinc was appropriate as per guidelines. Symptomatic drug use was also appropriate as per the guidelines because no lactobacillus/ racicadrotil/ antimotility/ antiemetic drugs were prescribed. Aantimicrobials were prescribed without identifying definitive cause for the diarrhoea in $46(85.19 \%)$ patients which is not as per the guidelines. So overall, only 8 (14.81\%) prescriptions from PHC was considered as appropriate as per the guidelines.

\section{Adverse drug reactions}

Out of these 140 patients, $4(2.85 \%)$ developed ADR. They all developed cutaneous ADR - maculopapular rashes all over the body with itching. They all fell in category of "possible" according to WHO causality assessment criteria. All can be attributed to use of antimicrobials which were used inappropriately so these ADRs could be preventable. They all received the treatment with antihistaminic drugs (cetirizine $5 \mathrm{mg}$ at bed time or Chlorphenaramine maleate $4 \mathrm{mg}$ once a day at bed time) orally and calamine lotion topically. All patients recovered from the ADRs with the given treatment. None of the ADR was reported from $\mathrm{PHC}$. 


\section{DISCUSSION}

It was observed that majority of the patients were males and around highest patients were below one year of age, which was also seen in other studies from India and western countries. ${ }^{13,16,17}$ Usually most children are weaned from breast feeding at an age of 4 to 6 months. There is increased risk of infection by faeco-oral route during this phase due to improper and unhygienic feeding practices. Also, while maternal antibodies are declining over this period and the child is yet to develop its own defenses against infections which makes this age more vulnerable. ${ }^{18}$ The predominance of diarrhoea in male children cannot be explained, but it is assumed that the male children were likely to be brought to the hospital for treatment than the females. This is an unfortunate but common practice in India which is also confirmed by other study from Kolkata showing that boys with diarrhoea were more likely to be given oral rehydration fluids than girls, and were more likely to be taken to qualified health professionals for treatment. ${ }^{19}$ Most inpatients $(75 \%)$ were fully immunized and some $(15 \%)$ were partially immunized as per the National immunization schedule. This reflects a general awareness among the caregivers about immunization and a good functional immunization program for children by health care providersbut still $8.57 \%$ of children were nonimmunized, which requires further evaluation.

The average duration of hospital stay in this study was 4.3 \pm 2.1 days which is similar to a study from a tertiary care hospital in Nepal. ${ }^{20}$ The average number of drugs/injections per encounter is an important index in prescribing practices. ${ }^{21}$ The values in our study are higher than the recommended limit of two drugs per encounter and the international average of 2.2 drugs per prescription. $^{22}$ A cluster survey conducted in under five children of acute diarrhoea at Bangladesh found that the average number of drugs prescribed per patient was 1.5; a figure much lower than that found in our study while a Nepal study found that the average number of drugs per pediatric inpatient was $4.5 \pm 3.7 .^{20,23}$ Hence, it is evident that the practice of polypharmacy is prevalent in our setup; thereby suggesting irrational prescribing practice in this regard. Polypharmacy practice is well known to be associated with drug related adverse drug reactions, medication errors, clinically significant drug interactions and an increased rate of admissions to hospital. The reasons for this practice could range from lack of accuracy/confidence in diagnosis, underuse of laboratory diagnostic services, easy availability of multiple antibiotics, or lack of awareness of the various treatment guidelines which needs further evaluation.

Rehydration fluids (100\%) and antimicrobials (94.29) were the most commonly prescribed drug groups. The average number of antimicrobials prescribed per inpatient in our study was $1.92 \pm 0.67$ with a range of 1 to 4 antimicrobials. Majority inpatients $(47.18 \%)$ received two antimicrobials during their hospital stay. When compared with other studies conducted in central Thailand and
Chennai, it was observed that antimicrobials were prescribed significantly more in our study $(\mathrm{P}<0.05) .{ }^{13,24}$ Cefotaxime and ceftriaxone was the most commonly used antimicrobial followed by amikacin in this study which is similar to the findings of a similar study from the same region. ${ }^{14}$ The use of antimicrobials was high in our study.

While all patients in our study were prescribed antimicrobials at tertiary centre, they were indicated only in $10(7.14 \%)$ patients with dysentery, enteric fever and septicemia. These patients could be treated effectively with one antibiotic as per both WHO and IAP guidelines but they were prescribed more than one antibiotic at a time. In our study, none of the patient received antimicrobials appropriately. Inappropriate use of antimicrobials in children with diarrhea has been reported by other researchers as well but extent is lower as compare to our study. A cross-sectional study conducted in 424 patients of diarrhoea at central region province of Thailand observed that $72.6 \%$ patients were inappropriately treated as per the guidelines. ${ }^{24}$ Injudicious use of antimicrobials observed in our study may be due to factors like doubtful diagnosis and underuse of laboratory investigations resulting in an empirical use of antimicrobials. While the exact reason needs further evaluation, this injudicious use of antimicrobials needs attention and appropriate interventions for rectification.

Appropriate use of ORS as well as intravenous rehydration fluids as per WHO and IAP guidelines was observed in most cases, except Isolyte $\mathrm{P}$ was used as replacement fluid in majority $(62.85 \%)$ rather than RL. Isolyte $\mathrm{P}$ is recommended in literature as a maintenance fluid in pediatric patients; however the WHO and IAP guidelines do not recommend this fluid for maintenance fluid therapy. A questionnaire based study conducted in emergency pediatric department at New Zealand and Australia found that $86 \%$ of physicians would use intravenous fluids in severe dehydration, most commonly half normal saline (with glucose) and normal saline. ${ }^{25}$

Zinc acetate was prescribed in around $80 \%$ inpatients at tertiary centre and $100 \%$ patients at PHC in this study which was better than the Chennai study $(65 \%) .{ }^{13} \mathrm{~A}$ questionnaire based national survey found that $16.9 \%$ of prescribers prescribe zinc supplements for treatment of diarrhoea. ${ }^{26}$ Zinc supplementsare recommended in patients of diarrhoea because it reduces the severity and frequency of diarrhoea.

In this study, fever was present in only 76 (54.29\%) patients, still antipyretic - paracetamol was prescribed to $99(70.71 \%)$ patients. Lactobacillus were prescribed to 85 $(60.71 \%)$ of patients, but none of the standard treatment guidelines supports its use. Also, $\mathrm{H}-2$ blockers ranitidine and famotidine were prescribed to $42.14 \%$ patients. Hyperacidity or drug induced gastritis is very uncommon entity in pediatric patients. Only the fear or assumption of developing gastritis with analgesic and antimicrobials has 
led to rampant use of antiacidity drugs in India, which needs attention of health care professionals.

On comparing the drug use at tertiary care centre and primary health care centre, it was found that antimicrobials were misused at PHCs also. Physicians at PHC tend to prescribe empirical antimicrobials without any investigations to patients. Most frequent antimicrobial was ofloxacin followed by metronidazole. PHC prescriptions were more rational all other aspects like use of ORS, zinc, supportive medicines etc. Possible reason for this could be less availability of drugs. At tertiary care centers, more number of patients with complications is received and also there is free availability of multiple antimicrobials which may add to misuse of drugs especially antimicrobials. WHO - Essential medicines list also suggest list of drugs to be available at tertiary care centers, but free availability of multiple drugs may contribute to misuse of drugs.

$4(2.85 \%)$ ADRs were reported to drugs prescribed mainly antimicrobials for acute gastroenteritis in our study. A review study of ADRs in pediatric patients estimated an overall incidence of ADRs in inpatients to be $9.53 \%$ and that in outpatients to be $1.46 \% .{ }^{27}$ Under-reporting of minor or non serious ADRs like nausea or vomiting which were either not detected or reported could contribute to low reporting in India. Also none of the ADR was reported from $\mathrm{PHC}$, which suggests there is a need for expansion of the awareness about the ADR reporting to the grass root level of health care.

The findings of this study suggested that a relatively rational approach to oral and parenteral rehydration therapy and zinc but inappropriate and overuse of antimicrobials, and other supplementary/symptomatic drugs in our study. However; further studies in this area are warranted before suggesting ways to reduce the economic impact of the disease. This is important for a centre like ours with a huge patient population, most of whom belong to the lower and lower middle socioeconomic groups. Some of the recommendations that may be made based on this study include reducing polypharmacy and empirical prescribing, encouraging rational prescribing and appropriate choice of drugs and their formulations.

Funding: No funding sources

Conflict of interest: None declared

Ethical approval: The study was approved by the Institutional Ethics Committee

\section{REFERENCES}

1. Johansson EW. Diarrhoea: Why children are still dying and what can be done. New York: UNICEF/WHO; 2009.

2. Unicef website: Recent report. Available at: http://data.unicef.org/child-health/diarrhoealdisease.html\#sthash.onAhCczU.dpuf, Updated: Apr 2016]
3. National Commission on Macroeconomics and Health. Burden of Disease in India. New Delhi: Ministry of Health and Family Welfare; 2005. Available at: https://nrhm-mis.nic.in/ui/who/PDF/ Report\%20of\%20the\%20National\%20Commission\% 20 on $\% 20$

Macroeconomics\%20and\%20Health\%202005.pdf. [Last accessed on 2015 Sep 28].

4. Bhargava R, Uppal S. Use of cold medications for upper respiratory tract infections in children. Pharmacoepidemiol Drug Saf. 2001;10:323-7.

5. Gupte S. The Short Textbook of Pediatrics. $10^{\text {th }}$ Ed. New Delhi: Jaypee Publishers; 2004:366.

6. Park K. Park's Textbook of Preventive and Social Medicine. $18^{\text {th }}$ Ed. Jabalpur: Bhanot Publishers; 2005:517.

7. Ghai OP, Paul VK, Bagga A. Essential Pediatrics. $7^{\text {th }}$ Ed. New Delhi: CBC Publishers; 2009:72.

8. World Health Organization. The treatment of diarrhoea: A manual for physicians and other senior health workers. $4^{\text {th }}$ rev. Department of Child and Adolescent Health and Development, Geneva: World Health Organization; 2005:4. Available at: http://whqlibdoc.who.int/publications/2005/9241593 180.pdf. [Last accessed on 2012 Nov 11].

9. Vlahovic-Palcevski V, Francetic I, Palcevski G, Novak S, Abram M, Bergman U. Antimicrobial use at a university hospital: Appropriate or misused? A qualitative study. Int $\mathbf{J}$ Clin Pharmacol Ther. 2007;45:169-74.

10. Bhatnagar S, Wadhwa N. Recent trends in the management of acute watery diarrhea in children. In: Bavdekar A, Matthai J, Sathiyasekaran M, Yachha SK, editors. IAP specialty series on Pediatric Gastroenterology. New Delhi: Jaypee Publishers. 2008:37-42.

11. Sanchez LA. Pharmacoeconomics. In: Dipiro JT, Talbent RL, editors. Pharmacotherapy. A pathophysiological approach. $6^{\text {th }}$ Ed. New Delhi: The McGraw-Hill; 2002:1-16.

12. United Nations Children's Fund. Diarrhoea: Why children are still dying and what can be done. Available at: http://www.unicef.org/media/files/Final_Diarrhoea_ Report_October_2009_fi nal.pdf. [Last accessed on 2015 Dec 15].

13. Balasubramanian S, Ganesh R. Prescribing pattern of zinc and antimicrobials in acute diarrhoea. Indian Pediatr. 2008;45:701.

14. Panchal JR, Desai CK, Iyer GS, Patel PP, Dikshit RK. Prescribing pattern and appropriateness of drug treatment of diarrhoea in hospitalised children at a tertiary care hospital in India. Int J Med Public Health. 2013;3:335-41.

15. World Health Organization (WHO). TheImportance on Pharmacovigilance. Safety Monitoring on Medicinal Products. Geneva(Switzerland): Office of Publications, World Health Organization; 2002. 
16. Conway SP, Phillips RR, Panday S. Admission to hospital with gastroenteritis. Arch Dis Child. 1990;65:579-84.

17. Tieder JS, Robertson A, Garrison MM. Pediatric hospital adherence to the standard of care for acute gastroenteritis. Pediatrics. 2009;124;1081-7.

18. World Health Organization (India); 1985. Available at:

http://www.whoindia.org/LinkFiles/GPP_Rational_U se_of_Medicines.pdf. [Last accessed on 2015 Sep 30].

19. Pandey A, Sengupta PG, Mondal S, Gupta D, Manna B, Ghosh S, et al. Gender differences in healthcareseeking during common illnesses in a rural community of west Bengal. India $\mathbf{J}$ Health Popul Nutr. 2002;20:306-11.

20. Shankar PR, Upadhyay DK, Subish P, Dubey A, Mishra P. Prescription patterns among paediatric inpatients in a teaching hospital in Western Nepal. Singapore Med J. 2006;47:261-4.

21. Karande S, Sankhe P, Kulkarni M. Patterns of prescription and drug dispensing. Indian $\mathbf{J}$ Pediatr. 2005;72:117-21.

22. Mummad J. Audit of paediatric prescriptions for the common paediatric problems. Pak J Med Sci. 2007;23:932-5.

23. Alam MB, Ahmed FU, Rahman ME. Misuse of drugs in acute diarrhea in under-fi ve children. Bangladesh Med Res Counc Bull. 1998;24:27-31.
24. Howteerakul N, Higginbotham N, Dibley MJ. Antimicrobial use in children under five years with diarrhea in a Central Region Province, Thailand. Southeast Asian J Trop Med Public Health. 2004;35:181-7.

25. Schutz J, Babl FE, Sheriff N, Borland M. Emergency department management of gastro-enteritis in Australia and New Zealand. J Paediatr Child Health. 2008;44:560-3.

26. Alameddine A, Mourad S, Rifai N. Management of acute gastroenteritis in healthy children in Lebanon A national survey. North Am J Med Sci. 2010;2:5127.

27. Impicciatore P, Choonara I, Clarkson A, Provasi D, Pandolfini C, Bonati M. Incidence of adverse drug reactions in pediatric in/outpatients: A systematic review and meta-analysis of prospective studies. $\mathrm{Br} \mathbf{J}$ Clin Pharmacol. 2001;52:77-83.

Cite this article as: Chaudhari VP, Patel J, Shah R, Shah A. Pharmacoepidemiological profile and appropriateness of drug use in paediatric diarrhoea patients: a cross sectional study in western India. Int J Basic Clin Pharmacol 2017;6:2062-9. 